\title{
MOLECULAR DETECTION OF AmpC $\beta$-LACTAMASE GENE IN Morganella morganii CLINICAL ISOLATES
}

\author{
AL-MUHANNA A.S. \\ Department of Laboratory Investigation, Faculty of Sciences, Kufa University, Iraq. \\ *Corresponding Author: Email- almuhannaabbas@yahoo.com
}

\author{
Received: October 27, 2013; Accepted: December 12, 2013
}

\begin{abstract}
Seventeen isolates of Morganella morganii were identified among three hundred ninety five of gram-negative bacteria that grown on MacConkey agar and isolated from different infections at Al-Najaf Al-ashraf province hospitals. The initial identification of Morganella morganii isolates depended on the colonial morphology, microscopic examination and biochemical tests. The final identification and antibiotic susceptibility testing were performed by using automated VITEK-2 compact system. The results of susceptibility revealed that Morganella morganii isolates were highly resistant to most common antibiotics and considered to be multi-drug resistant (MDR). To detect AmpC $\beta$-lactamase enzymes, phenotype methods were used. Eleven and five isolates were AmpC producers according to initial and confirmatory methods, respectively. The genotype method was used to detect bla $a_{\text {Amp }}$ gene using Polymerase Chain Reaction (PCR) technique. The results revealed that 7 $(41.2 \%)$ of Morganella morganii isolates possess bla

Keywords- Morganella morganii, $\beta$-lactamase, AmpC, VITEK-2, PCR.
\end{abstract}

Citation: Al-Muhanna A.S. (2013) Molecular Detection of AmpC $\beta$-Lactamase Gene in Morganella morganii Clinical Isolates. International Journal of Microbiology Research, ISSN: 0975-5276 \& E-ISSN: 0975-9174, Volume 5, Issue 7, pp.-506-509.

Copyright: Copyright@2013 Al-Muhanna A.S., et al. This is an open-access article distributed under the terms of the Creative Commons Attribution License, which permits unrestricted use, distribution and reproduction in any medium, provided the original author and source are credited.

\section{Introduction}

The gram-negative rod Morganella morganii is only the species of the genus Morganella, which belongs to the tribe Proteeae of the family Enterobacteriaceae, in addition to Proteus and Providencia [1]. M. morganii become an important opportunistic nosocomial pathogen that proved by Williams, et al. [2] when bacteremia cases due to this organism had been recorded in a cardiac surgery unit of the Bristol Royal Infirmary. Reports of nosocomial outbreaks have revealed that infection with $M$. morganii can lead to major clinical problems, which are usually associated with common causes of catheter-associated bacteriuria, infections of the urinary and hepatobiliary tracts [3].

The first bacterial enzyme reported to destroy penicillin was the AmpC $\beta$-lactamase of Escherichia coli, although it had not been so named in 1940 [4]. AmpC $\beta$-lactamases are cephalosporinases that are poorly inhibited by clavulanic acid. They are clinically significant because they may confer resistance to a wide variety of $\beta$-lactam antibiotics that including a-methoxy- $\beta$-lactams (cephamycins) such as cefoxitin, narrow, broad and expanded-spectrum cephalosporins, $\beta$-lactam- $\beta$-lactamases inhibitor combinations and aztreonam $[5,6]$.

Like other members of the Enterobacteriaceae, M. morganii has a natural resistance to $\beta$-lactam antibiotics and many strains of it are resistant to the $\beta$-lactam drugs 1999 [7]. There are no studies published that $M$. morganii produce AmpC $\beta$ - lactamase, however, several studies were detected plasmid-mediated AmpC $\beta$-lactamase that has its origin in the chromosomal ampC gene of $M$. morganii (blaDHA) in others genus, such as Barnaud, et al. [8] was detected in
Salmonella enteritidis, Verdet, et al. [9] was detected in Klebsiella spp. Adler, et al. [10] was detected in Escherichia coli.

\section{Materials and Methods \\ Specimens Collection}

A total of 800 clinical samples were collected during the study period from November, 2012 to February, 2013. The samples were obtained from patients suffering from urinary tract infections, ear infections and respiratory tract infections at Al- Najaf Al-Ashraf province hospitals.

\section{Identification of Morganella Morganii Isolates}

The initially identification of suspected $M$. morganii isolates were recovered from clinical specimens depend on cultural characteristics, microscopic appearance and biochemical tests which included (oxidase, catalase, indole, methyl red, voges-proskauer, citrate utilization, kligler iron agar, urease, motility and gelatin liquefaction) tests. The final identification was performed with automated VITEK 2 compact system using Gram Negative - Identification (GN-ID) cards.

\section{Antibiotic Susceptibility Test}

Performed with the automated VITEK-2 compact system based on Minimum Inhibitory Concentration (MIC) technique determination using AST-N093 cards (bioMérieux, France). This card contained the following antibiotics, piperacillin, ticarcillin, piperacillintazobactam, ticarcillin-clavulanic acid, cefepime, ceftazidime, aztreonam, imipenem, meropenem, amikacin, isepamicin, tobramycin, 
gentamicin, pefloxacin, ciprofloxacin, trimethoprim-sulfamethoxazole, minocycline, colistin and rifampicin.

\section{Phenotypic Detection of Plasmid Mediated AmpC $\beta$-Lactamase}

M. morganii isolates were tested for cefoxitin susceptibility using standard disk diffusion method [11]. The resistant isolates $(\leq 14 \mathrm{~mm}$ inhibition zone diameter) were considered as initially AmpC $\beta$ lactamase producers [12].

AmpC disk test was used as a confirmatory test to detect plasmidmediated AmpC $\beta$-lactamase [13].

\section{PCR Amplification for bla Ampc $_{\text {gene }}$}

Plasmid DNA was purified using the wizard of GET ${ }^{\mathrm{TM}}$ plasmid miniprep kit (G-BIOSCIENCES, USA). The purified plasmidic DNA that extracted from $M$. morganii isolates used as a template for PCR amplification depending on the protocol of KAPA Biosystem manufacturer's instruction (2006).

\section{Results}

A total of 800 clinical samples were obtained from 400 patients with urinary tract infections, ear and respiratory tract infections. However, $395(49.4 \%)$ of samples gave positive results for bacterial growth versus $405(50.6 \%)$ samples showed no bacterial growth. The initial identification was depended on the colonial morphology. Microscopic examination and The biochemical tests were considered as a complementary of the initial diagnosis of $M$. morganii isolates [3].

The final identification was performed with the automated VITEK-2 compact system by using GN-ID cards. The results demonstrate that only seventeen isolates (4.3\%) were confirmed as M. morganii out of the total number of growth of gram-negative bacteria on MacConkey agar $(n=395)$. These isolates obtained from different clinical infections were represented by $10(58.8 \%)$ isolates from urinary tract infections, $5(29.4 \%)$ and $2(11.8 \%)$ isolates from ear infections and respiratory tract infections, respectively.

The results of antibiotic susceptibility test were revealed that the resistant of isolates to piperacillin and ticarcillin were recorded in $(100 \%)$ and $(64.7 \%)$, respectively. The resistance to $\beta$-lactam/ $\beta$ lactamase inhibitor combinations was appeared in all isolates $(100 \%)$ to piperacillin-tazobactam and $(47 \%)$ of isolates were resistant to ticarcillin-clavulanic acid. High percentage rates of resistant appeared to cephalosporins that represented by ceftazidime, cefepime and cefoxitin were detected in (100\%), (94.1\%) and $(64.7 \%)$ of isolates, respectively. $(100 \%)$ of isolates were resistant to aztreonam. The low resistance was appeared in carpbapenems that represented by $5.9 \%$ to each of imipenem and meropenem (were the most effective $\beta$-lactam antibiotics). The most aminoglycosides showed moderate effect against $M$. morganii isolates were represented by amikacin $(70.5 \%)$, isepamicin $(64.7 \%)$, tobramycin $(53 \%)$ and gentamicin $(23.5 \%)$. The resistance to fluoroquinolones was recorded in $(88.2 \%)$ to pefloxacin and $(64.7 \%)$ of isolates were resistant to ciprofloxacin. The resistance rate of isolates to the trimethoprim-sulfamethoxazole was $(76.5 \%)$ and $(94.1 \%)$ for minocycline. All isolates (100\%) were resistant to both colistin and rifampicin.

The results of phenotybic detection of plasmid mediate AmpC $\beta$ Lactamase indicated that $11(64.7 \%)$ isolates were resistant to cefoxitin which suspected as AmpC $\beta$-lactamase producers, while 2 $(11.8 \%)$ were intermediate and $4(23.5 \%)$ were sensitive. AmpC $\beta$ lactamase production was confirmed in all M. morganii isolates by
AmpC disk test. AmpC producer isolates were observed in 5 $(29.4 \%)$ of the 17 isolates. All isolates that show positive result to AmpC disk test were cefoxitin resistant. The results revealed that $12(70.6 \%)$ isolates were none AmpC $\beta$-lactamase producer; including $6(54.5 \%)$ resistant to cefoxitin, $2(100 \%)$ intermediate resistant and $4(100 \%)$ isolates were susceptible to cefoxitin.

Polymerase chain reaction was used to determine bla $a_{A m p}$ gene in all the M. morganii isolates. However, The results of PCR bla gene amplification was appear in $7(41.2 \%)$ isolates [Fig-1]. Five of these isolates were cefoxitin resistance and identified as AmpC $\beta$ lactamase producers by AmpC disk test, while one of the two remaining isolates was intermediate and the last one was susceptible to cefoxitin and identified as negative AmpC $\beta$-lactamase producers by phenotypic test [Fig-2].

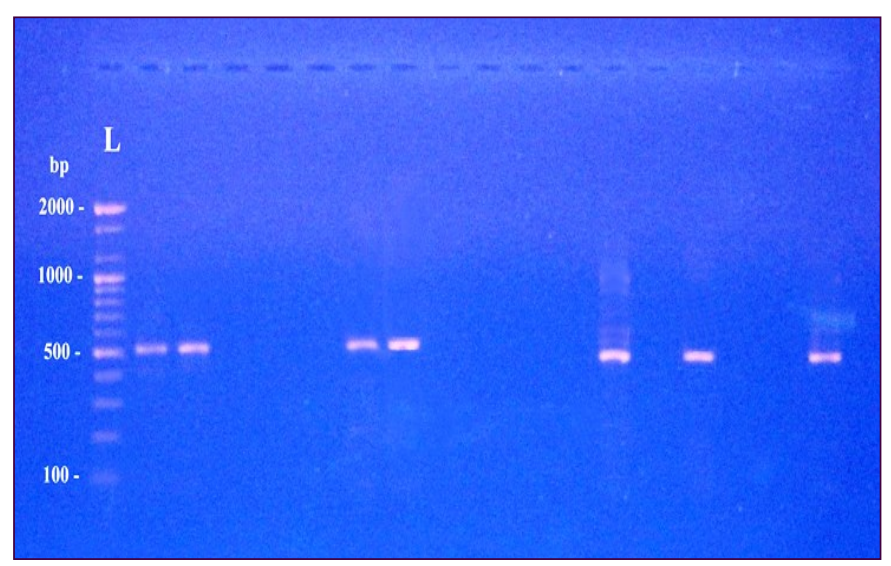

Fig. 1- PCR amplification products of blampC gene for M. morganii isolates with product $510 \mathrm{bp}$. Lane (L), DNA molecular size marker (2000-bp ladder)

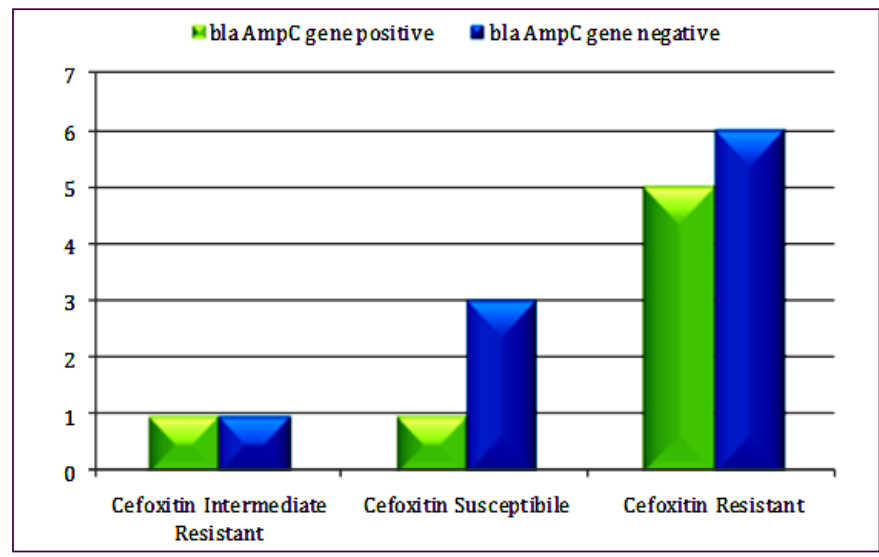

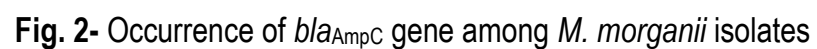
$(n=17)$

\section{Discussion}

Eight handred clinical isolates were obtained from patients suffering from urinary tract, ear and respiratory tract infections, after cultured on MacConky agar (49.4\%) of samples gave positive results for bacterial growth versus $405(50.6 \%)$ samples showed no bacterial growth probably due to previous antibiotic therapy or prior present other microorganisms such as gram-positive cocci and grampositive bacilli that could not grew on MacConkey agar [14]. The initial identification was depended on the colonial morphology. The colonies of M. morganii were grown on blood agar and nutrient agar appears off-white and opaque in color and pale like shaped when 
grown on the MacConkey agar, indicated that M. morganii is unable to ferment lactose sugar. Microscopic examination has revealed that $M$. morganii was gram-negative non-sporulated and noncapsulated rods [15]. The biochemical tests were considered as a complementary of the initial diagnosis of M. morganii isolates [3].

The final identification was performed with the automated VITEK-2 compact system by using GN-ID cards. (4.3\%) of isolates were confirmed as $M$. morganii out of the total number of growth of gramnegative bacteria on MacConkey agar $(n=395)$. These isolates obtained from urinary tract infections, ear infections and respiratory tract infections.

The results of $M$. morganii isolates to common antibiotics revealed highly resistance for most of antibiotic and considered as multi drug resistance. The resistance to ceftazidime and cefepime may be due to production of ESBLs enzymes, the major causes of cefoxitin resistant are encoding of plasmid mediated AmpC $\beta$-lactamase, but cefoxitin resistance may also be mediated by alterations to outer membrane permeability [16].

In Iraq, there is only one previous report which showed M. morganii isolates were resistant to gentamicin, trimethoprimsulfamethoxazole, penicillin and piperacillin [15]. In China Cai, et al. [17] reported that $M$. morganii isolates were resistant to penicillins, aztreonam and ciprofloxacin. There are many factors may have contributed to such high rates of resistance including misuse of antibiotics by health care professionals or non-skilled practitioners, misuse of antibiotics by the general public and inadequate surveillance due to lack of information arising from routine antimicrobial susceptibility testing, like reports from other developing countries.

AmpC disk test was estimated for detection of plasmid mediated AmpC $\beta$-lactamases Black, et al. [13] reported that the AmpC disk test exhibited $100 \%$ sensitivity and $98 \%$ specificity for detection of plasmid mediated AmpC $\beta$-lactamases. On the other hand, the phenotypic data pointed that all $\mathrm{AmpC}$ positive isolates were previously recorded as cefoxitin resistant. However, this test was unable to show the possibility of AmpC production in cefoxitin susceptible and intermediate resistant isolates. This may be because the AmpC disk test is based on permeabilization of cell membrane and release $\beta$-lactamases into the external environment [18]. This test perhaps is not sensitive to low level expression enzymes.

Parveen, et al. [19] showed that $22 \%$ of AmpC producers isolates were susceptible to cefoxitin. AmpC production in these isolates could be due a mechanism similar to that of ESBL producing organism that appear susceptible to ceftazidime by the disc diffusion method [19].

In present study $54.6 \%$ of cefoxitin resistance isolates were bla AmpC negative [Fig-2]. Cefoxitin resistance in AmpC non-producers could be due to some other mechanisms such as, lack of permeation of porins $[4,19]$. Sometimes cefoxitin resistance may be caused by the production of certain carbapenemases and a few types of class $A \beta$ lactamases rather than AmpC enzyme production [20].

Genes for AmpC $\beta$-lactamases are commonly found on the chromosomes of the several members of the family Enterobacteriaceae, including Enterobacter, Shigella, Providencia, Citrobacter freundii, Morganella morganii, Serratia marcescens and Escherichia coli. Plasmid mediated AmpC $\beta$-lactamases has arisen through the transfer of chromosomal genes for the inducible AmpC $\beta$ lactamases on to plasmids. This transfer has resulted in plasmid mediated AmpC $\beta$-lactamases $[19,21,22]$.
Plasmid mediated AmpC $\beta$-lactamases represent a new threat since they confer resistance to cephamycins and are not affected by commercially available $\beta$-lactamase inhibitors and can in strains with loss of outer membrane porins, provide resistance to carbapenems. This resistance mechanism has been found around the world can cause nosocomial outbreaks, appears to be increasing in prevalence and merits further study to define the best options for detection and treatment $[19,23]$.

\section{Conclusion}

Moganella morganii is important opportunistic pathogen causing different infections, all isolates are multi drug resistance, 11 of isolates were AmpC $\beta$-lactamase producers according to phenotybic detection of AmpC $\beta$-Lactamase, PCR amplification the bla AmpC gene were detected in 7 isolates.

\section{References}

[1] Chen Y.T., Peng H.L., Shia W.C., Hsu F.R., Ken C.F., Tsao Y.M. and Ku T.H. (2012) BMC Genomics, 13(Suppl 7), S4.

[2] Williams E.W., Hawkey P.M., Penner J.L., Senior B.W. and Barton L.J. (1983) Journal of Clinical Microbiology, 18(1), 5-9.

[3] O'Hara C.M., Brenner F.W. and Miller J.M. (2000) Clinical Microbiology Reviews, 13(4), 534-546.

[4] Hernández-Allés S., Benedí V.J., Martínez-Martínez L., Pascual Á., Aguilar A., Tomás J.M. and Albertí S. (1999) Antimicrobial Agents and Chemotherapy, 43(4), 937-939.

[5] Rodríguez-Martínez J.M., Pascual A., García I. and MartínezMartínez L. (2003) Journal of Antimicrobial Chemotherapy, 52, 703-706.

[6] Abraham E.P. and Chain E. (1940) Nature, 146, 837.

[7] Poirel L., Guibert M., Girlich D., Naas T. and Nordmann P. (1999) Antimicrob. Agents Chemother., 43(4), 769-776.

[8] Barnaud G., Arlet G., Verdet C., Gaillot O., Lagrange P.H. and Philippon A. (1998) Antimicrob. Agents Chemother., 42(9), 2352 $-2358$.

[9] Verdet C., Benzerara Y., Gautier V., Adam O., Ould-Hocine Z. and Arlet G. (2006) Antimicrob. Agents Chemother., 50(2), 607617.

[10]Adler H., Fenner L., Walter P., Hohler D., Schultheiss E., Oezcan S. and Frei R. (2008) Journal of Antimicrobial Chemotherapy, 61(2), 457-458.

[11]Clinical and Laboratory Standards Institute (CLSI) (2012) Performance Standards for Antimicrobial Susceptibility Testing; Twenty-second Informational Supplement, 32(3). Wayne, USA.

[12]Coudron P.E., Hanson N.D. and Climo M.W. (2003) J. Clin. Microbiol., 41, 772-777.

[13]Black J.A., Moland E.S. and Thomson K.S. (2005) J. Clin. Microbiol., 43, 3110-3113.

[14]Al-Muhannak F.H.N. (2010) Spread of some extendedspectrum beta-lactamases in clinical isolates of Gram-negative bacilli in Najaf, M.Sc. thesis. College of Medicen, Kufa University, Iraq.

[15]Auda J.G., Al-Grawi I.G. (2009) Al-Kindy Col. Med. J., 5(1): 3235.

[16]Tan T.Y., Ng L.S.Y., He J., Koh T.H. and Hsu L.Y. (2009) Antimicrob. Agents Chemother., 53(1), 146-149. 
[17]Cai J.C., Yang W., Hu Y.Y., Zhang R., Zhou H.W. and Chen G.X. (2012) Diagnostic Microbiology and Infectious Disease, 73, 207-209.

[18]Basak S., Khodke M., Bose S. and Mallick S.K. (2009) J. of Cli. and Dia. Res., 3, 1921-1927.

[19]Parveen M.R., Harish B.N. and Parija S.C. (2010) Brazilian Journal of Microbiology, 41, 596-602.

[20]Jacoby G.A. (2009) Clinical Microbiology Reviews, 22(1), 161182.

[21]Medeiros A.A. (1997) Clin. Infect. Dis., 24(1), 19-45.

[22]Subha A.V., Devi R. and Ananthan S. (2003) Indian J. Med. Res., 117, 13-18.

[23]Philippon A., Arlet G. and Jacoby G.A. (2002) Antimicrob. Agents Chemother., 46(1), 1-11.

[24]Madigan M.T. and Martinko J.M. (2006) Biology of Microorganisms. Pearson Prentice Hall, Upper Saddle River.

[25]Messai Y., Benhassine T., Naim M., Paul G. and Bakour R. (2006) Rev. Esp. Quimoterap., 19, 144-151. 